\title{
Acta
Biochimica
Polonica
}

Vol. 51 No. $3 / 2004$

$693-702$

QUARTERLY

\section{In vivo gene transfer using cetylated polyethylenimine}

\author{
Aleksander Sochanik ${ }^{凶}$, Tomasz Cichoń, Monika Makselon, Małgorzata Stróżyk, \\ Ryszard Smolarczyk, Joanna Jazowiecka-Rakus and Stanisław Szala
}

\section{Department of Molecular Biology, Center of Oncology, Maria Sktodowska-Curie Memorial Institute, Gliwice, Poland}

Received: 13 November, 2003; revised: 13 February, 2004; accepted: 25 February, 2004

Key words: modified PEI, cationic lipids, non-viral vectors, gene transfer

This report describes gene transfer in vitro as well as in vivo using cetylated low-molecular mass $(600 \mathrm{Da})$ polyethylenimine $(28 \%$ of amine groups substituted with cetyl moieties), termed CT-PEI. This compound is hydrophobic and has to be incorporated into liposomes in order to be suitable for gene transfer studies. Serum-induced plasmid DNA degradation assay demonstrated that CT-PEI-containing liposomal carriers could protect complexed DNA (probably via condensation). In vitro luciferase gene expression achieved using medium supplemented with $10 \%$ serum was comparable to that achieved in serum-reduced medium and was highest for CT-PEI/cholesterol liposomes, followed by CT-PEI/dioleoylphosphatidylcholine liposomes and PEI 600 Da (uncetylated) carrier. In vivo systemic transfer into mice was most efficient when liposome formulations contained CT-PEI and cholesterol. Higher luciferase expression was then observed in lungs than in liver.

In conclusion: liposomes containing cetylated polyethylenimine and cholesterol are a suitable vehicle for investigating systemic plasmid DNA transfer into lungs.

A continuous need exists for constructing more efficient non-viral vectors allowing

transfer of therapeutic genes. Such vectors might be useful for studies exploring inhibi-

\footnotetext{
Study supported by grants PBZ-KBN 004/P04/98 and 3 P05A 04422 from the State Committee for Scientific Research (KBN, Poland).

${ }^{凶}$ Corresponding author: Aleksander Sochanik, Department of Molecular Biology, Center of Oncology, Maria Skłodowska-Curie Memorial Institute, 44-101 Gliwice, Poland; tel.: (48 32) 278 9750; fax: (48 32) 278 3512; e-mail: asochanik@io.gliwice.pl

Abbreviations: Chol, cholesterol; CT-PEI, cetylated polyethylenimine 600 Da; DOPE, dioleoylphosphatidylethanolamine; DPPC, dipalmitoylphosphatidylcholine; FBS, fetal bovine serum; LAL, Limulus Amebocyte Lysate; LPS, lipopolysaccharide (endotoxin); PEG, polyethylene glycol; PEI, polyethylenimine; RLU, relative luminescence units.
} 
tion of angiogenesis, promotion of apoptosis, destruction of target cells by activated pro-drugs, restoration of cellular sensitivity to growth inhibitors or destruction of cancer cells' metastatic abilities (Luo \& Saltzman, 1999; Pedroso de Lima et al., 2000). More efficient and target-specific vectors should also be non-immunogenic and pose negligible risk of genetic recombination (see for example: Erbacher et al., 1999; Kichler et al., 2000; Oupicky et al., 2001; Hood et al., 2002; Kircheis et al., 2002). They would be an alternative to viral carriers (retroviruses, adenoviruses, adeno-associated viruses, herpesviruses, lentiviruses and hybrid /retro-adeno/ viruses, see for example: Benihoud et al., 1999; Monahan \& Samulski, 2000; Trono, 2000 ) as well as to the clinically cumbersome physical methods.

A more widespread use of synthetic carriers has been hampered so far by the fragility of DNA-carrier complexes in robust biological environments (e.g. blood) (Dash et al., 1999; Li et al., 1999; Eliyahu et al., 2002) resulting in relative inefficiency of DNA transfer.

Non-viral carriers take advantage of the chemical properties exhibited by certain compounds capable of binding to DNA and forming complexes that can readily adsorb onto cell surface and become endocytosed. Most importantly, such compounds are cationic in nature (Godbey et al., 1999; Barron et al., 1999).

Among the well known non-viral carriers of this kind are polyethylenimines. They are linear or branched polymers with a considerable density of positive surface charge (Godbey et $a l .$, 1999). They are particularly effective in terms of DNA transfer to the cells. This probably results from the PEIs exhibiting the so-called "proton sponge effect". Upon endosomal $\mathrm{pH}$ decrease, increased PEI protonation leads to osmotic swelling and then bursting of the endosomes. As a result, the PEI-DNA complexes are released into the cytoplasm.
There have been numerous attempts to modify polyethyleneimines in order to increase their targeting specificity. Suitable examples are provided by polyethyleneimine with an Arg-Gly-Asp (RGD) motif-containing peptide ligand, recognized by cellular integrin receptors (Erbacher et al., 1999), polyether-polyethylenimine graft copolymers (Nguyen et al., 2000) or PEG-transferrin-PEI complexes (Ogris et al., 1999). Other derivatives, such as alanine-substituted and dodecylated PEI were also synthesized (Thomas \& Klibanov, 2002).

A PEI derivative obtained by partially substituting amine groups with cetyl moieties (CT-PEI) was used to prepare liposomes with increased resistance against the degrading activity of serum proteins (Yamazaki et al., 2000).

The purpose of this study was to investigate suitability of CT-PEI for in vivo DNA transfer. By substituting amine groups of a low-molecular-mass polyetylenimine with cetyl residues a derivative was obtained which, unlike the hydrophilic PEI, was used to prepare liposomal formulations together with such neutral lipids as phosphatidylethanolamine (PE) or phosphatidylcholine (PC), or with cholesterol.

Preliminary toxicity screening in vitro of such liposomes showed no adverse effects upon the cell lines studied. A series of in vitro experiments followed in order to optimize transfer conditions (DNA amount, carrier-to-DNA ratio). Finally, systemic in vivo studies of luciferase reporter gene transfer into mouse lungs and liver were performed.

\section{MATERIALS AND METHODS}

CT-PEI synthesis. Synthesis of cetylated polyethylenimine (CT-PEI) was performed according to Yamazaki et al. (2000). In brief, the synthesis was initiated by reacting Epomin (low-molecular-mass polyethylenimine 600, 
Nippon Shokubai Ltd., Japan) with cetyl bromide (Sigma-Aldrich, Milwaukee, WI, U.S.A.) in the presence of triethylamine for $12 \mathrm{~h}$ at $63^{\circ} \mathrm{C}$. The product was dialyzed, first against $40 \%$ ethanol and then water. Finally, it was lyophilized. The end product was ${ }^{1} \mathrm{H}$ NMR-analyzed using a Unity Inova-300 spectrometer operating at $300 \mathrm{MHz}$ (Institute of Organic Chemistry and Technology, Silesian Technical University in Gliwice, Poland) with deuterated chloroform as solvent and tetramethylsilane as reference.

CT-PEI liposomes. The liposomes were prepared by mixing aliquots of chloroform solutions $(10 \mathrm{mg} / \mathrm{ml})$ of CT-PEI and other lipids (DOPE, DPPC or cholesterol) at appropriate molar ratios and spin-evaporating the resulting preparations. Dry lipid film was hydrated at $4^{\circ} \mathrm{C}$ for $16 \mathrm{~h}$ and sonicated with a tip probe until the emulsion began to clear (two or three 1-min cycles, medium power, Branson sonifier). The sonicated liposomes were then extruded using gas-tight glass Hamilton syringes and a hand-held extrusion device fitted with two polycarbonate membranes of 100-nm pore size (Sigma).

DNA preparations. pVR1255 plasmid DNA containing luciferase reporter gene from Photinus pyralis, under the control of CMV promoter was kindly provided by Dr. R. H. Zaugg (Vical Inc., San Diego, CA, U.S.A.). The plasmids were isolated from DH5 $\alpha$ E. coli (Gibco-BRL) cultures using a procedure developed by Horn et al. (1995). Crude plasmid DNA was endotoxin-purified on a Sephacryl $\mathrm{S} 1000$ column $(\mathrm{h}=100 \mathrm{~cm}, \mathrm{ID}=1.6 \mathrm{~cm}, 150$ $\mathrm{cm}^{3}$ packed bed) and ethanol-precipitated. The endotoxin content in purified DNA preparations was assessed spectrophotometrically using the Limulus Amebocyte Lysate (LAL) reagent (BioWhittaker). One microgram of DNA preparation typically contained 0.03-0.04 LPS units.

Serum-induced degradation tests. Migration retardation of CT-PEI-liposome-complexed plasmid DNA was characterized in 1\% agarose gel (not shown). Optimized (i.e. capa- ble of protecting plasmid DNA) complex formulations were tested for stability in the presence of $10 \%$ serum. Aliquots of $2 \mu \mathrm{g}$ pVR 1255 plasmid DNA were incubated for $15 \mathrm{~min}$ at room temperature with increasing amounts of liposomes. Fetal bovine serum (FBS, final conc. $=10 \%)$ was added to the complexes formed. The samples were incubated for $4 \mathrm{~h}$ at $37^{\circ} \mathrm{C}$. The complexes were subsequently treated with EDTA (final conc. $=10 \mathrm{mM}$ ), SDS (final conc. $=0.5 \%$ ) and incubated for 20 min at $55^{\circ} \mathrm{C}$. Plasmid DNA was phenol/chloroform- extracted and precipitated before performing electrophoresis.

Cell culture. Studies of transfection efficiency were performed using three cell lines: B16(F10) (murine melanoma) and Renca (murine renal cell carcinoma), both obtained from Wistar Institute (Philadelphia, PA, U.S.A.), and HeLa (human cervical epithelioid carcinoma) obtained from the Institute of Immunology and Experimental Therapy, Polish Academy of Sciences (Wroclaw, Poland). Cells were grown in T-25 (Corning) flasks in RPMI 1640 medium supplemented with 10\% FBS and antibiotics (streptomycin at $100 \mu \mathrm{g} / \mathrm{ml}$ and ampicillin at $100 \mathrm{U} / \mathrm{ml}$ ), at $37^{\circ} \mathrm{C}$ and $5 \% \mathrm{CO}_{2}$.

In vitro transfection studies. One day prior to transfection cells were seeded in 24-well plates, at $5 \times 10^{4}$ cells/well. When the cells reached about $80 \%$ confluence, appropriate dilutions of CT-PEI/DOPE liposomes or PEI were prepared in $100 \mu \mathrm{l}$ final volume using polystyrene tubes (Sarstedt). Separately, appropriate dilutions of $2 \mu \mathrm{g}$ plasmid DNA in $150 \mathrm{mM} \mathrm{NaCl}$ were prepared, using identical volumes and tubes. The carrier emulsions were added dropwise to DNA solutions and the tube was gently mixed. Following 30 -min incubation at room temperature, $850 \mu \mathrm{l}$ of suitable medium (RPMI+Fbs, RPMI-FBS or Opti-MEM) was added to each sample. The transfection mixtures were then transferred to the wells, following removal of growth medium. Cells were next incubated for $4 \mathrm{~h}$ at $37^{\circ} \mathrm{C}$ and $5 \% \mathrm{CO}_{2}$. At the end of in- 
cubation, the transfection medium was replaced with regular growth medium. After 24 $\mathrm{h}$ cells in each well were lysed using a Promega kit-provided lysis buffer.

In vivo transfection studies. In vivo transfer of CT-PEI-containing complexes into mice was performed as follows: aliquots of pVR1255 plasmid DNA were complexed to aliquots of polycarbonate membrane-extruded (100 nm nominal pore size) liposomes in 5\% dextrose, by adding plasmid DNA dropwise to liposomal emulsion. Six- to eight-week-old C57 BL/6 mice were injected $600 \mu \mathrm{l}$ of the above transfection mix containing varying amounts of plasmid DNA and liposomes. This volume was required to accommodate the complex components without causing precipitation. The animals were sacrificed at various time-points after injection of complexes in order to recover lung and liver tissues. The tissues were rinsed with ice-cold $\mathrm{PBS}^{-}$and homogenized in Promega lysis buffer. Samples were centrifuged at 15000 r.p.m. at $4^{\circ} \mathrm{C}$ and supernatant aliquots were assessed for luciferase activity.

Determining luciferase enzymatic activity in cell lysates. After $24 \mathrm{~h}$ the cultures in each well were lysed using the Luciferase Assay System buffer (Promega). The lysates were centrifuged for $30 \mathrm{~min}$ at 15000 r.p.m. and $4^{\circ} \mathrm{C}$, supernatants $(100 \mu \mathrm{l})$ transferred into fresh test tubes and luciferase activity determined, using a Berthold luminometer, after adding $100 \mu \mathrm{l}$ aliquots of enzyme substrate to the lysates ( $20 \mu \mathrm{l}$ or less). Protein content in the lysates was measured by the Bradford method using a kit from BioRad (and bovine serum albumin as a standard).

\section{RESULTS}

\section{Synthesis of cetylated polyethylenimine}

The cetyl derivative of polyethylenimine (CT-PEI) was synthesized as described in Ma- terials and Methods. The synthesized yellowish compound was insoluble in water; following dialysis it became white (yields usually varied between 60 and $70 \%$ ).

\section{${ }^{\mathbf{1}} \mathbf{H}$ NMR analysis of CT-PEI}

The structure of the synthesized compound and the number of substituted amine groups were confirmed by ${ }^{1} \mathrm{H}$ NMR. The degree of substitution in different syntheses was found to be similar (between 22 and 28 mole \%). The spectrum shown in Fig. 1 refers to one of the syntheses. The triplet at 0.881 p.p.m. corresponds to $-\mathrm{CH}_{3}$ from the cetyl substituents. The multiplet between 1.15-1.56 p.p.m. corresponds to the remaining protons from the cetyl substituents, except for the protons at the carbon atom linked to the amine group; the latter signals overlap the multiplet (2.3-3.3 p.p.m.) from protons of PEI ethyl groups $\left(-\mathrm{CH}_{2}-\mathrm{CH}_{2}-\right)$. Signal intensities represented as integration curves proportional to the number of hydrogen atoms in corresponding moieties demonstrate that the synthesized CT-PEI contains, on average, 14 ethylene units and 4 cetyl groups. This corresponds to 28 mole\% substitution yielding stoichiometric formula where $\mathrm{m}=14 \mathrm{C}_{2} \mathrm{H}_{4}$ $\mathrm{N})_{\mathrm{m}}\left(\mathrm{C}_{16} \mathrm{H}_{33}\right)_{0.22-0.28 \mathrm{~m}}$.

\section{Stability of CT-PEI-containing complexes in the presence of serum}

CT-PEI liposomes were prepared as described in Materials and Methods. The stability of the complexes in the presence of $10 \%$ serum was investigated for CT-PEI/ DOPE (0.65:1, mol/mol) (not shown); CT-PEI/ DPPC/Chol (0.65:1:1, by mol) (not shown) and for CT-PEI/Chol (1:1, mol/mol) (Fig. 2).

Complexes formed at the liposome/DNA (w/w) ratios 4:1 and higher (lanes 7-10) are able to protect plasmid DNA against degradation by $10 \%$ serum during a 4 -h incubation at 


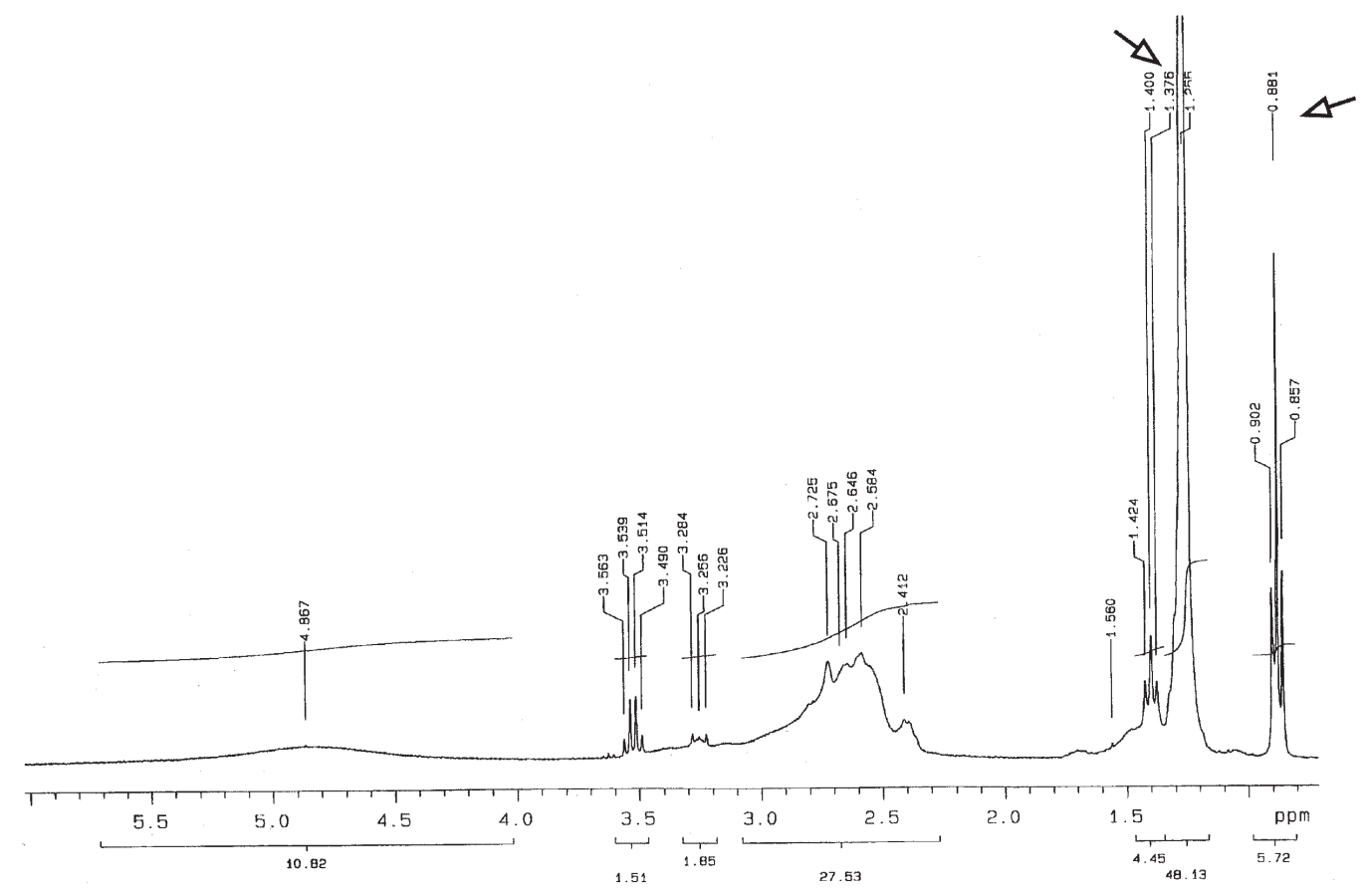

Figure 1. ${ }^{1} \mathrm{H}$ NMR spectrum of CT-PEI.

Note peaks (triplet at 0.881 p.p.m. and multiplet at 1.15-1.56 p.p.m.) indicative of the presence of cetyl moieties in CT-PEI (arrows). See Results for details.

$37^{\circ} \mathrm{C}$. Lower ratio formulations, i.e. 1:1 through 3:1 (lanes 1-6) do not protect DNA completely (Fig. 2).

\section{In vitro transfection of neoplastic cell lines}

In vitro transfections of the luciferase reporter gene (Fig. 3) were performed in the presence of $10 \%$ serum using either uncetylated poliethylenimine (control) or CT-PEI liposomes formulated with either DOPE or cholesterol. Three different cell lines were used: (B16(F10), HeLa and Renca (only the first is shown).

Luciferase expression, which indirectly illustrates the efficiency of gene transfer, was lowest when plasmid DNA was complexed to uncetylated PEI, compared to both liposomal formulations. CT-PEI liposomes containing DOPE yielded the reporter gene expression higher by one order of magnitude. When DOPE was substituted with cholesterol, luciferase expression in cells transfected using

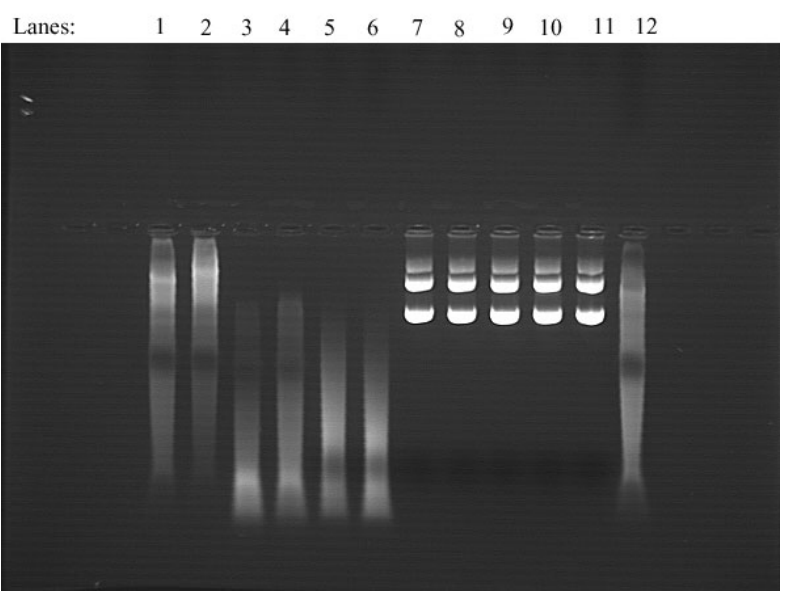

Figure 2. Protection assay of plasmid DNA by complexes containing CT-PEI/Chol liposomes following exposure to $10 \%$ serum.

Aliquots $(2 \mu \mathrm{g})$ of pVR1255 DNA were mixed with increasing amounts of liposomes; the resulting complexes were then exposed to $10 \%$ serum $(4 \mathrm{~h})$ following which DNA was extracted from samples and electrophoresed, as described in Materials and Methods. Legend: $2 \mu \mathrm{g}$ CT-PEI/Chol liposomes 1:1 (mol/mol) (lanes 1-2); $4 \mu \mathrm{g}$ (lanes 3-4); $6 \mu \mathrm{g}$ (lanes 5-6); $8 \mu \mathrm{g}$ (lanes 7-8); $10 \mu \mathrm{g}$ (lanes 9 and 10); uncomplexed plasmid DNA (lane 11); uncomplexed and serum-exposed plasmid DNA (lane 12). 


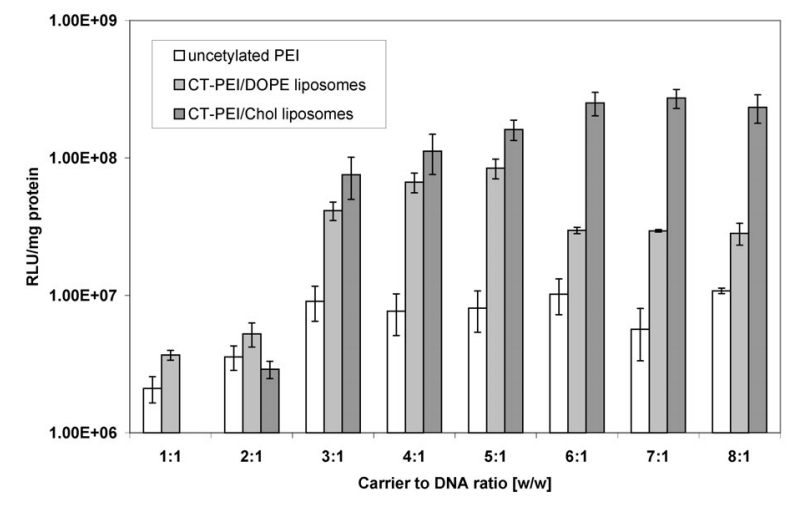

Figure 3. Luciferase gene expression in B16(F10) murine melanoma cells following in vitro transfer (in the presence of serum) of plasmid DNA complexed to uncetylated PEI or CT-PEI-containing liposomes.

Complexes were formed containing $1 \mu \mathrm{g}$ of pVR1255 (DNA amount optimization data not shown) and different amounts of PEI or CT-PEI liposomes. Complexes were formed either in Opti-MEM (not shown) or in RPMI medium supplemented with $10 \%$ FBS. The complexes were used to transfect cells seeded on 24-well plates, as described in Materials and Methods. Each bar represents mean $( \pm$ S.D.) of triplicate determinations of luminescence. Open bars: uncetylated PEI-600; light grey bars, optimized lipoplexes containing CT-PEI/DOPE 0.65:1 (mol/mol); dark grey bars, optimized lipoplexes containing CT-PEI/Chol 1:1 ( $\mathrm{mol} / \mathrm{mol}$ ); composition of both lipoplexes was previously optimized in separate experiments (not shown).

serum-containing medium was the highest (above $5 \times 10^{8} \mathrm{RLU} / \mathrm{mg}$ protein) and comparable to that seen in the absence of serum (not shown). CT-PEI/cholesterol liposomes were chosen for in vivo studies.

\section{In vivo gene transfer into mice}

Transfer of plasmid DNA containing the luciferase reporter gene was also attempted in vivo, using $\mathrm{C} 57 \mathrm{Bl} / 6$ mice. Mice were given a single intravenous injection (tail) of liposome carrier-plasmid DNA complexes formed at a chosen weight ratio of liposomes to plasmid DNA (see Materials and Methods for details).

As a plasmid carrier in vivo, CT-PEI liposomes formulated with cholesterol (1:1, $\mathrm{mol} / \mathrm{mol}$ ) were chosen. It had been initially found that addition of phosphatidylcholine (DPPC) to CT-PEI/cholesterol liposomes did not augment luciferase expression neither when a comparable amount of the cationic component was used in the formulation nor at the ratio previously proposed by Yamazaki et al. (2000) (not shown).

The time course of the reporter gene expression following administration of complexes formed at a constant weight ratio of liposomes to plasmid DNA was first determined in lungs and livers at various time points following injection. It was found (Fig. 4) that luciferase expression was highest $24 \mathrm{~h}$ after complex administration and that lungs were consistently transfected more efficiently than liver.

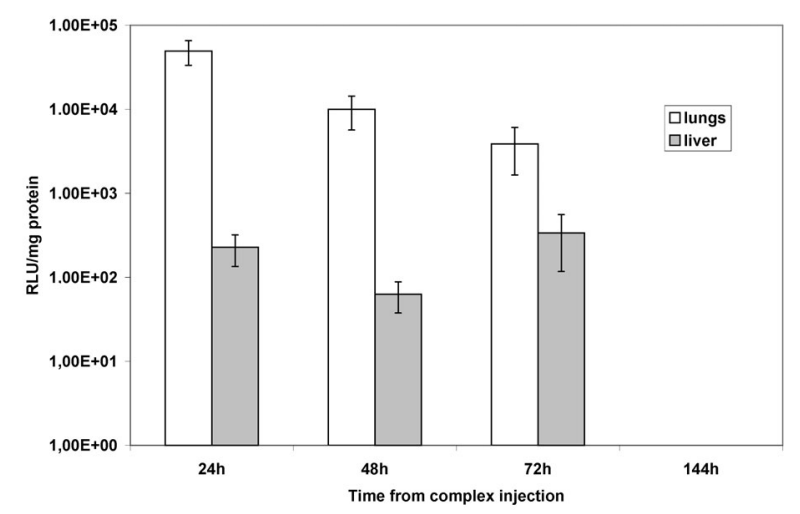

Figure 4. Kinetics of luciferase gene expression in murine lungs and liver following in vivo transfer of plasmid DNA complexed to extruded CT-PEI/Chol (1:1, mol/mol) liposomes.

Complexes containing $60 \mu \mathrm{g}$ of pVR1255 (DNA amount optimization data: see Fig. 5) and $360 \mu \mathrm{g}$ extruded liposomes were injected (in $600 \mu \mathrm{l}$ total volume of $5 \%$ dextrose) intravenously (tail) to $6-8$ week-old C57 Bl/6 mice. Animals were sacrificed at indicated time points after complex administration and luciferase activity was measured in lung and liver tissue homogenates. Each bar represents mean ( \pm S.D.) of triplicate determinations of luminescence.

The dependence of luciferase expression in the lung and liver upon the DNA dose administered was also investigated (Fig. 5). Eighty micrograms of plasmid DNA was found to be 


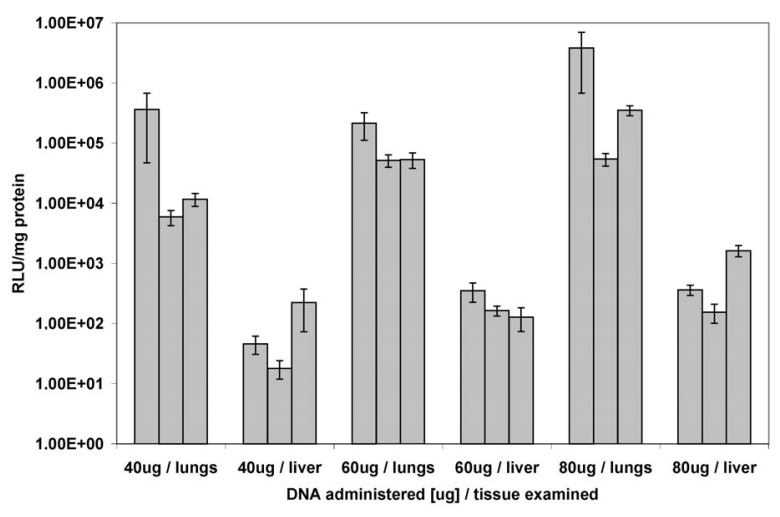

Figure 5. Distribution of luciferase gene expression as a function of plasmid DNA dose as assessed in murine lungs and liver following in vivo transfer of plasmid DNA complexed to extruded CT-PEI/Chol liposomes.

Complexes containing the indicated amounts of pVR1255 and varying amounts of extruded CT-PEI/Chol (1:1, mol/mol) liposomes (keeping the DNA/lipids weight ratio at 1:6; complex optimization not shown) were injected as described in Materials and Methods and Fig. 4. Animals were sacrificed at $24 \mathrm{~h}$ post complex administration and luciferase activity was measured in lung and liver tissue homogenates. Each bar represents mean ( \pm S.D.) of triplicate determinations of luminescence.

the highest administrable dose. Higher amounts of DNA caused complex precipitation when the indicated volume was used, while larger volumes were detrimental to mice. Therefore, the amount of $60 \mu \mathrm{g}$ of plasmid DNA was adopted for further in vivo studies.

\section{DISCUSSION}

The present report describes in vitro and in vivo studies of plasmid DNA transfer achieved with a liposomal carrier containing cetylated polyethylenimine (CT-PEI), a novel low-molecular-mass cationic polymer. The goal of this study was to assess the suitability of this compound for systemic gene transfer as well as to establish its in vivo targets.

Cetylated PEI was synthesized according to a protocol published by Yamazaki et al.
(2000). ${ }^{1} \mathrm{H}$ NMR spectra showed that $22-28$ mole \% of PEI amine groups were successfully substituted with cetyl moieties. The latter value obtained in one of the syntheses is somewhat higher than the one originally reported (see Fig. 1).

The cetyl derivative of PEI, due to its hydrophobic nature, has to be formulated into liposomes in order to be useful for DNA transfer. In our study the liposomes, besides CT-PEI, contained either DOPE or cholesterol (and in some cases also DPPC).

All three investigated liposomal formulations were able to complex plasmid DNA. Complex formation, presumably accompanied by DNA condensation, has long been regarded as imparting to DNA resistance against degradation by serum. The ability of these liposomes to protect DNA was checked by studying electrophoretic migration patterns of plasmid DNA aliquots extracted from complexes that had been previously exposed to $10 \%$ serum (Fig. 2). The CT-PEI-containing complexes effectively protected transferred DNA at certain liposome/DNA ratios. A stepwise increase of retardation ability, similar to that seen in Fig. 2, was repeatedly noticed in several experiments. Its nature requires explanation; this was not, however, the goal of our study.

The applicability of the studied liposomes for DNA transfer was further examined in a series of in vitro transfection experiments, in the presence of serum (Fig. 3). They showed that CT-PEI polycationic liposomes were suitable for in vitro DNA transfer, matching the efficiencies obtainable either with high molecular mass PEIs or with other well established liposomal formulations (e.g. Bragonzi et al., 1999; Sochanik et al., 1999). In our hands, the best were CT-PEI liposomes formulated with cholesterol at $1: 1(\mathrm{~mol} / \mathrm{mol})$, as opposed to 0.65:1 ( $\mathrm{mol} / \mathrm{mol})$ CT-PEI/DOPE previously proposed by Yamazaki et al. (2000). In that study DNA transfer was higher in the presence of serum. Here we confirm similar relationships for HeLa and Renca cell lines (re- 
sults not shown). Transfection of B16(F10) cells with CT-PEI liposomes in the presence of serum yielded luciferase gene expression that was decreased by half to one order of magnitude.

Several investigators have pointed out the composition and stoichiometric formulae of nonviral carriers, carrier to DNA weight ratios, volumes, media used, etc., as crucial factors for successful DNA transfer in vivo (see for example: Liu et al., 1997; Loisel et al., 2001). After having established the kinetics of luciferase gene expression (Fig. 4) we determined an optimum safe dose of administered plasmid DNA (Fig. 5). Our results in vivo fully confirmed the essential significance of the mentioned parameters. In our hands, the three-component liposomes (CT-PEI, cholesterol and DPPC) described by Yamazaki et al. (2000) were not as effective in transfecting lungs as the liposomes containing just CT-PEI and cholesterol.

The efficiency of gene transfer with non-targeted complexes depends on the amount of the complexes reaching cells in target tissues. Destructive interactions between the elecrostatically unshielded cationic complexes and blood components may require increased quantities of carrier to be administered in order to achieve efficient gene transfer. Yet, biosafety considerations limit the tolerable doses of both plasmid DNA and carrier (Senior et al., 1991; Eliyahu et al., 2002). We thus explored another possibility of increasing transfer efficiency in vivo by preinjecting cationic liposomes (results not shown). This approach had been used previously by other investigators (Liu et al., 1995; 1997; Song et al., 1998). In fact, it did increase expression of the reporter gene but higher expression was offset by marked toxicity in mice, most likely resulting from the total dose of cationic lipid administered. For our in vivo studies we used liposomes extruded through 100-nm pore polycarbonate membranes. This markedly improved luciferase expression, especially in the lungs that are, it has to be remem- bered, the first capillary bed encountered by complexes upon intravenous tail injection. Volumes required to achieve successful injection of such tolerable liposome/DNA complex quantities (without causing precipitation) were in our experiments close to the borderline values reported (Thierry et al., 1995; Goula et al., 1998; 2000; Loisel et al., 2001).

In summary, low-molecular mass PEI substituted with hydrophobic cetyl moieties was formulated into cationic liposomes either with DOPE or with cholesterol, or with both phosphatidylcholine and cholesterol. Such liposomes can be used as efficient DNA carriers for transfecting various cell lines in vitro. Extruded CT-PEI-containing liposomes formulated with cholesterol proved effective in systemic gene transfer in vivo allowing marked reporter gene expression in murine lungs.

The authors wish to thank Dr. A. Rajca for performing the NMR study, Mmes M. Krawczyk and H. Paterak for their excellent technical assistance.

\section{R E F E R E N C E S}

Barron LG, Uyechi LS, Szoka Jr FC. (1999) Cationic lipids are essential for gene delivery mediated by intravenous administration of lipoplexes. Gene Ther.; 6: 1179-83.

Benihoud K, Yeh P, Perricaudet M. (1999) Adenovirus vectors for gene delivery. Curr Opin Biotechnol.; 10: 440-7.

Bragonzi A, Boletta A, Biffi A, Muggia A, Sersale G, Cheng SH, Bordignon C, Assael BM, Conese M. (1999) Comparison between cationic polymers and lipids in mediating systemic gene delivery to the lungs. Gene Ther:; 6: 1995-2004.

Dash PR, Read ML, Barrett LB, Wolfert MA, Seymour LW. (1999) Factors affecting blood clearance and in vivo distribution of polyelectrolyte complexes for gene delivery. Gene Ther.; 6: 643-50. 
Eliyahu H, Servel N, Domb AJ, Barenholz Y. (2002) Lipoplex-induced hemagglutination: potential involvement in intravenous gene delivery. Gene Ther.; 9: 850-8.

Erbacher P, Remy JS, Behr JP. (1999) Gene transfer with synthetic virus-like particles via the integrin-mediated endocytosis pathway. Gene Ther.; 6: 138-45.

Godbey WT, Wu KK, Mikos AG. (1999) Poly(ethylenimine) and its role in gene delivery. J Control Release.; 60: 149-60.

Goula D, Benoist C, Mantero S, Merlo G, Levi G, Demeneix BA. (1998) Polyetyleniminebased intravenous delivery of transgenes to mouse lung. Gene Ther:; 5: 1291-5.

Goula D, Becker N, Lemkine GF, Normandie P, Rodrigues J, Mantero S, Levi G, Demeneix BA. (2000) Rapid crossing of the pulmonary endothelial barrier by polyethylenimine/DNA complexes. Gene Ther.; 7: 499-504.

Hood J, Bednarski M, Frausto R, Guccione S, Reisfeld RA, Xiang R, Cheresh DA. (2002) Tumor regression by targeted gene delivery to the neovasculature. Science.; 296: 2404-7.

Horn N, Meek AJ, Budahaza G, Marquet M. (1995) Cancer gene therapy using plasmid DNA: purification of DNA for human clinical trials. Hum Gene Ther.; 6: 565-73.

Kichler A, Frisch B, Lima de Souza D, Schuber F. (2000) Receptor-mediated gene delivery with non-viral DNA carriers. J Liposome Res.; 10: 443-60.

Kircheis R, Wightman L, Kursa M, Ostermann E, Wagner E. (2002) Tumor-targeted gene delivery: an attractive strategy to use highly active effector molecules in cancer treatment. Gene Ther.; 9: 731-5.

Li S, Tseng WC, Beer Stolz D, Wu SP, Watkins SC, Huang L. (1999) Dynamic changes in the characteristics of cationic lipidic vectors after exposure to mouse serum: implications for intravenous lipofection. Gene Ther; 6 : 585-94.

Liu Y, Liggitt D, Zhong W, Tu G, Gaensler K, Debs R. (1995) Cationic liposome-mediated intravenous gene delivery. $\mathrm{J}$ Biol Chem.; 270: 24864-70.
Liu F, Qi H, Huang L, Liu D. (1997) Factors controlling the efficiency of cationic lipid-mediated transfection in vivo via intravenous administration. Gene Ther; 4: 517-23.

Loisel S, Floch V, Le Gall C, Ferec C. (2001) Factors influencing the efficiency of lipoplexes mediated gene transfer in lung after intravenous administration. $J$ Liposome Res.; 11: 127-38.

Luo D, Saltzman M. (1999) Synthetic DNA delivery systems. Nat Biotechnol.; 18: 33-7.

Monahan PE, Samulski RJ. (2000) AAV vectors: is clinical success on the horizon? Gene Ther.; 7: 24-30.

Nguyen HK, Lemieux P, Vinogradov SV, Gebhart CL, Guerin N, Paradis G, Bronich TK, Alakhov VY, Kabanov AV. (2000) Evaluation of polyether-polyethylenimine graft copolymers as gene transfer agents. Gene Ther:; 7: 126-38.

Ogris M, Brunner S, Schuller S, Kircheis R, Wagner E. (1999) PEGylated DNA/transferrin-PEI complexes: reduced interaction with blood components, extended circulation in blood and potential for systemic gene delivery. Gene Ther.; 6: 595-605.

Oupicky D, Carlisle RC, Seymour LW. (2001) Triggered intracellular activation of disulfide-crosslinked polyelectrolyte gene delivery complexes with extended systemic circulation in vivo. Gene Ther.; 8: 713-24.

Pedroso de Lima MC, Simoes S, Pires P, Faneca H, Duzgunes N. (2000) Cationic lipid-DNA complexes in gene delivery: from biophysics to biological applications. $A d v$ Drug Deliv Rev.; 47: 277-94.

Senior JH, Trimble KR, Maskiewicz R. (1991) Interaction of positively-charged liposomes with blood: implications for their application in vivo. Biochim Biophys Acta.; 1070: 173-9.

Sochanik A, Kaida I, Mitrus I, Rajca A, Szala S. (1999) A new cholesterol derivative suitable for transfecting certain type of cells in the presence of $10 \%$ serum. Cancer Gene Ther.; 7: 513-20.

Song YK, Liu F, Liu D. (1998) Enhanced gene expression in mouse lung by prolonging the 
retention time of intravenously injected plasmid DNA. Gene Ther.; 5: 1531-7.

Thierry AR, Lunardi-Iskandar Y, Bryant JL, Rabinovich P, Gallo RC, Mahan LC. (1995) Systemic gene therapy: Biodistribution and long-term expression of a transgene in mice. Proc Natl Acad Sci USA.; 92: 9742-6.

Thomas M, Klibanov AM. (2002) Enhancing polyethylenimine's delivery of plasmid DNA into mammalian cells. Proc Natl Acad Sci USA.; 99: 14640-5.

Trono D. (2000) Lentiviral vectors: turning a deadly foe into a therapeutic agent. Gene Ther.; 7: 20-3.

Yamazaki Y, Nango M, Hasegawa Y, Hasegawa M, Oku N. (2000) Polycation liposomes, a novel nonviral gene transfer system, constructed from cetylated polyethylenimine. Gene Ther.; 7: 1148-55. 